\title{
Underwater Endoscopic Mucosal Resection of a Large Flat Adenoma with Pseudoinvasion in the Rectum
}

\author{
Ana Ponte $^{a}$ Rolando Pinho ${ }^{a}$ Luísa Proença ${ }^{a}$ Joana Silva ${ }^{a}$ Jaime Rodrigues ${ }^{a}$ \\ Mafalda Sousa $^{a}$ Xiaogang Wen $^{\mathrm{b}}$ Agostinho Sanches $^{\mathrm{b}}$ João Carvalho ${ }^{\mathrm{a}}$ \\ Departments of a Gastroenterology and b Pathology, Centro Hospitalar Vila Nova de Gaia/Espinho, \\ Vila Nova de Gaia, Portugal
}

\section{Keywords}

Pseudoinvasive adenoma · Underwater endoscopic mucosal resection $\cdot$ Rectum

\section{Mucosectomia Underwater de Lesão Plana \\ Adenomatosa com Pseudo-Invasão no Reto}

\section{Palavras Chave}

Adenoma pseudo-invasivo · Mucosectomia underwater . Reto

A 69-year-old male with no relevant personal and family medical history was admitted for endoscopic resection of a rectal laterally spreading tumor. Colonoscopy revealed a $30-\mathrm{mm}$ pseudodepressed, laterally spreading tumor (Paris classification 0-IIa+IIc) with granular and nongranular components. A high-definition colonoscope (CF-H180AL; Olympus Medical Systems, Hamburg, Germany) was used to examine the lesion and its margins using white-light (Fig. 1a) and narrow-band imaging (Fig. 1b) to evaluate the mucosal and vascular patterns, which were regular. Subsequently, an underwater endoscopic mucosal resection (UEMR) was performed, as this technique enables resection of larger fragments and obviates the need of submucosal injection, which is sub- optimal in pseudodepressed lesions. Air insufflation was switched off, luminal air was aspirated, water was instilled using the water jet until complete immersion of the lumen was achieved (Fig. 2a), and the lesion was resected in piecemeal fashion using a conventional 25-mm oval snare (CJ-ADR-23-230-025; Nova LightSystems, Life Partners Europe, Bagnolet, France) and usual electrosurgical settings (Endocut effect 2, ICC 200; ERBE Elektromedizin, Tübingen, Germany) (Fig. 2b, c). A bleeding vessel was identified during the procedure (Fig. 3a) and managed with a hemostatic clip (Fig. 3b). Histological analysis revealed a tubulovillous adenoma with high-grade dysplasia and rare adenomatous glands within the submucosa extending from the overlying epithelium, with no associated desmoplastic reaction, corresponding to an adenoma with misplaced epithelium (Fig. 1c). A follow-up procedure performed 3 months later revealed no residual lesion.

Water immersion preserves the circular configuration of the muscularis propria of the colon while folds of mucosa and submucosa project into the lumen away from the muscle layer, avoiding the need for submucosal injection used in conventional EMR [1, 2]. Bleeding during UEMR is uncommon, and the point of origin is clearly identified underwater [1].

Adenoma with misplaced epithelium is a rare entity formerly known as pseudoinvasive adenoma, which corresponds to an extension of the adenomatous glands of an adenoma into the submucosa through minor defects of the muscularis mucosae $[3,4]$. The distinction of this entity from an invasive cancer in which neoplastic epithelium, such as desmoplasia, frank atypia, or pleomorphism, is present in the submucosa may be difficult but is crucial as the management and prognosis of an adenoma with misplaced epithelium is identical to an adenomatous polyp [3, 4].

Dr. Ana Ponte

Department of Gastroenterology, Centro Hospitalar Vila Nova de Gaia/Espinho Rua Conceição Fernandes

PT-4434-502 Vila Nova de Gaia (Portugal)

E-Mail ana.ilponte@gmail.com
(C) 2017 Sociedade Portuguesa de Gastrenterologia Published by S. Karger AG, Basel Karger

0 pen access

This article is licensed under the Creative Commons AttributionNonCommercial-NoDerivatives 4.0 International License (CC BYNC-ND) (http://www.karger.com/Services/OpenAccessLicense). Usage and distribution for commercial purposes as well as any distribution of modified material requires written permission. 

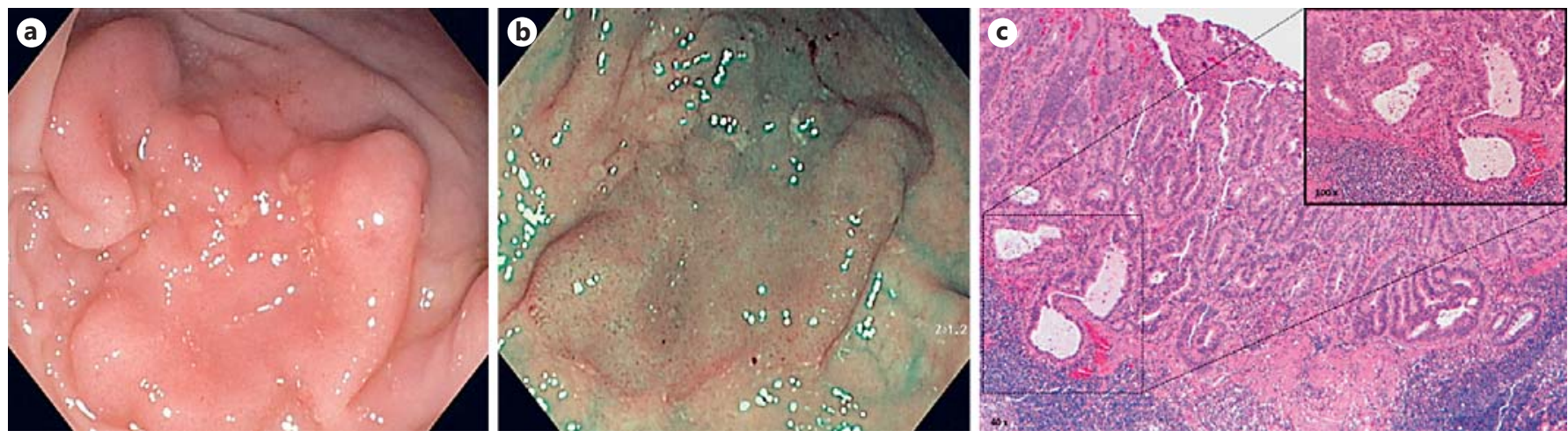

Fig. 1. a Endoscopic image using white light, showing a pseudodepressed, laterally spreading tumor (Paris classification 0-IIa+IIc) with granular and nongranular components. b Endoscopic image using narrow-band imaging. c Histological image (H\&E. $\times 40$ magnification) showing a tubulovillous adenoma with rare areas of pseudoinvasion. Inset One area of pseudoinvasion is further amplified to $\times 100$, highlighting an adenomatous gland within the submucosa extending from the overlying epithelium with no associated desmoplastic reaction.
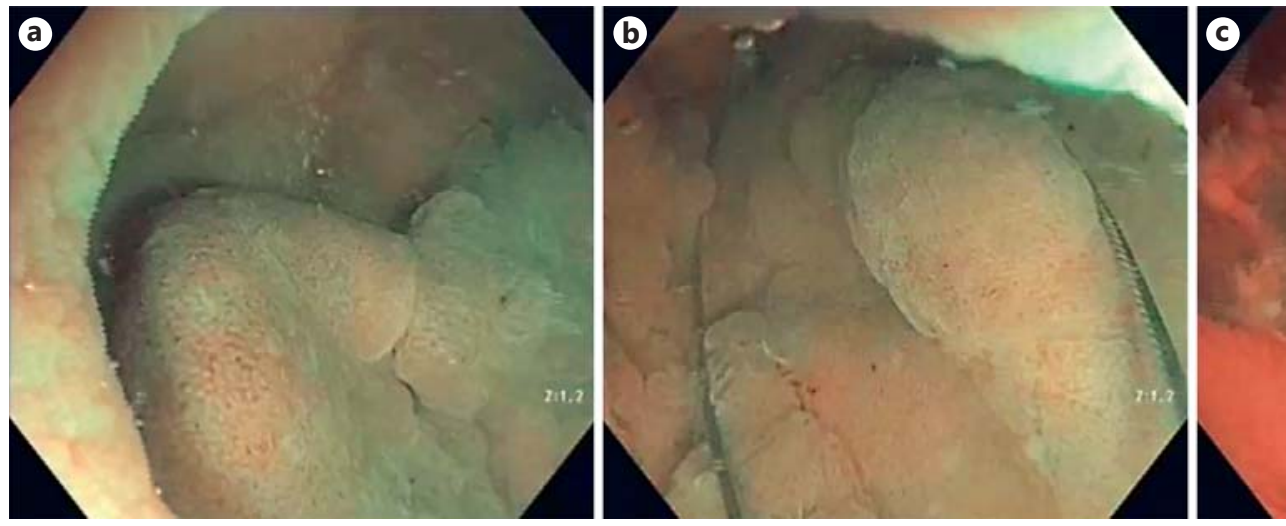

men was achieved. b Endoscopic image depicting the resection of the lesion in piecemeal fashion, using a conventional oval snare. c Endoscopic image revealing the final scar.
Fig. 3. a Endoscopic image revealing a bleeding vessel from the scar of the resected lesion, which is clearly identified underwater. b Endoscopic image depicting the final scar with a hemostatic clip placed in the bleeding spot.
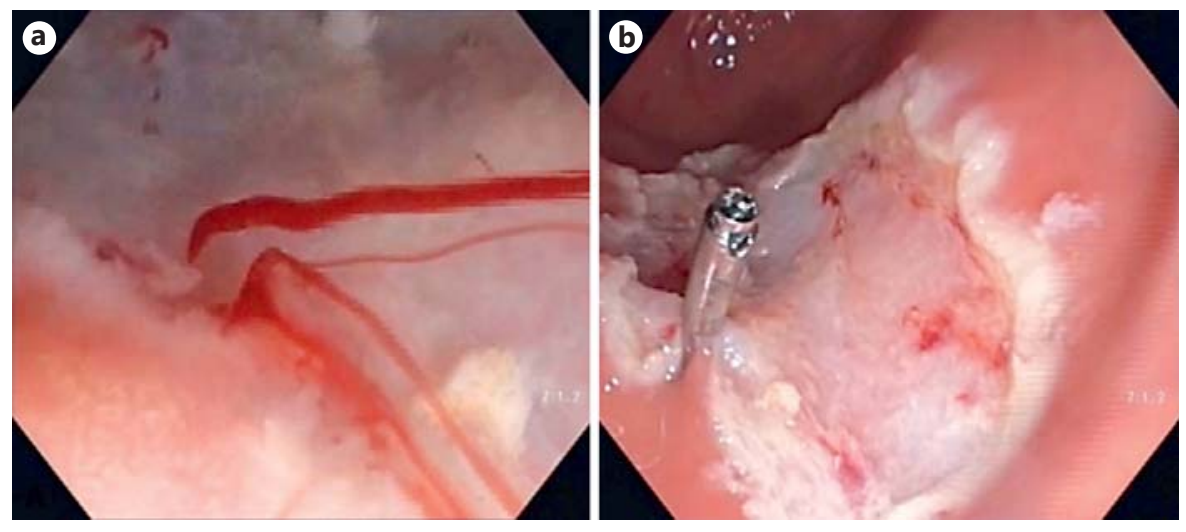
This case required informed consent but did not require review/approval by the appropriate ethics committee.
The authors have no conflicts of interest to declare.
References
1 Binmoeller KF, Weilert F, Shah J, Bhat Y, Kane S: "Underwater" EMR without submucosal injection for large sessile colorectal polyps (with video). Gastrointest Endosc 2012; 75:1086-1091.

2 Uedo N, Nemeth A, Johansson GW, Toth E, Thorlacius H: Underwater endoscopic mucosal resection of large colorectal lesions. Endoscopy 2015;47:172-174.
3 Ferreira da Silva MJ, Pinho R, Wen X, Tente D, Leite S, Carvalho J: Adenoma with pseudoinvasion - a crucial differential diagnosis for invasive adenocarcinoma. Gastroenterol Hepatol 2017;4D:96-98.

4 Rodrigues J, Pinho R, Wen X: Two synchronous pseudoinvasive adenomas - twice the caution? GE Port J Gastroenterol 2016; 23: 324-325. http://dx.doi.org/10.1016/j. jpge.2016.03.005.
UEMR of a Large Flat Adenoma with Pseudoinvasion in the Rectum 